\title{
A Conceptual Analysis of Social Networking and its Impact on Employee Productivity
}

\author{
Benjamin B. Aguenza ${ }^{1,2}$, Ahmad Puad Mat Som ${ }^{1}$ \\ ${ }^{I}$ Academic Support Department, Al Faisal University, Prince Sultan College for Tourism \& Business, Saudi \\ Arabia. \\ ${ }^{2}$ Post-Graduate Student, School of Health Science, Management and Pedagogy, Southwestern University, \\ Philippines. \\ ${ }^{I}$ Travel \& Tourism Management Department, Al Faisal University, Prince Sultan College for Tourism \& \\ Business, Saudi Arabia.
}

\begin{abstract}
Social networking site is all about awareness and connection, and presently the social networking site (SNS) seems to be the mantra that affects the productivity of employee in the workplace. The new media is growing so fast that it makes it imperative for employees to embrace the medium. The purpose of the study is to investigate the relevance of collaborative technology such as social networking to employee productivity in the workplace. The conceptual paper examines positive and negative perceptions of social networking sites, provides the relationship between social networking and employee productivity and examines whether social networking are capable of increasing the levels of employee performance and satisfaction. It was discovered that the use of social networks at work helped employees improve their productivity, but numerous studies also found the opposite. Thus, organizations should comprehend about social networking before educating their employees and setting appropriate policies at workplace.
\end{abstract}

Keywords: employee performance, employee productivity, employee satisfaction and social networking sites.

\section{INTRODUCTION}

Social networking is a way in which many individuals come together and form many sized groups. These groups may be big, small, formal, informal, intentional or unintentional. When organized method through which groups are formed, help is acquired, information is conveyed, and actions are taken to achieve certain outcomes. When it comes to online social networking, sites are commonly used. These sites are known as social networking sites. SNS has led to fundamental changes in the ways people interact in both the employee and organization (Martensen et al., 2011). New media of communication such as e-mail, forum and chat applications have altered the entire process chains (Picot and Neuburger, 2000). It was argued that social networking sites in particular have had a profound effect by changing the nature of efficiency of communication processes in both business and private life (Beck, 2007).

Platforms such as Facebook, Twitter, MySpace and LinkedIn are available for everyone in the world. It was traditionally created to connect with individuals from all over the world. This includes employees, friends and families. However, as the number of users increase to millions, organizations are also trying to connect with employees more so than ever. For example, Facebook has 845 million active users in 2012 around the world, with Europe recorded the highest users (223 million users) followed by Asia (184 million). The distributions of users by gender were $57 \%$ females and $43 \%$ males, 425 million users were connected through mobiles, and each user spent 20 minutes per visit, according to Fach (2012). These indicate the increasingly popularity of social networking sites among users and are still attracting thousands of new users daily.

Broadly, SNSs design a special computer-generated platform through which social relations are characterized and enacted from a user approach. It can be defined as web-based services that allow employee to: (i) construct a public or semi-public profile within a bounded system, (ii) articulate a list of other users with whom they share a connection, and (iii) view and traverse their list of connections and those made by others within the system (Boyd and Ellison, 2008). The purpose of the study is to investigate the relevance of collaborative technology such as social networking site to employee productivity in the workplace. The conceptual paper examines positive and negative perceptions of social networking sites, provides the relationship between social networking site and employee productivity, and examines whether social networking site are capable of increasing the levels of employee performance and satisfaction.

\section{LITERATURE REVIEW}

www.iosrjournals.org 
Long before social networking site became the commercialized mass information and entertainment juggernaut it is today, it was accessible to the general public, and certainly many years before Al Gore claimed he "took the initiative of creating it", the internet and its predecessor were a focal point for social interactivity (Snopes.com, 2005). Any activities where humans share stories and influence others can pretty much be considered social networking (Nicholson, 2011). Social networking such as Facebook is a great forum for discussing mutual topics of interest, and perhaps even meeting or renewing acquaintances with other humans virtually. According to Greenwald (2009) and Deloitte (2009), 55\% of employees visit a social networking site at least once a week. Given these percentages of using SNS without considering what implications might be for the employer, organizations should also take a look some insights of telecommunication medium at present.

\subsection{SIGNIFICANCE OF SNS TO ORGANIZATIONS}

Most people think that social networking sites such as Facebook, Twitter, MySpace and LinkedIn as time-wasters; however, a number of studies have shown just the opposite. Using SNS may actually increase employee productivity. A number of studies show that employees who use social networking sites are $9 \%$ more productive than those who do not (Fahmy, 2009). Employee who are more social by nature and are connected to other people through social networking sites are better persons in the workplace, which means they are skilled at interacting with others and solving problems. In a similar study by Fahmy (2009), he found that 70\% who used internet for personal surfing resulted in sharpened employee's concentration. It is assumed that by taking short breathers, the brain will be refreshed and renewed.

In a related development, AT\&T, a company that sells internet connection services, conducted an independent survey of 2,500 employees in five European countries. Of employees using social networking sites: $65 \%$ SNSs made themselves more efficient workers, $46 \%$ SNSs gave them more creative and ideas, $38 \%$ SNSs helped them gain knowledge and come up with solutions to problems, 36\% SNSs allowed them collect knowledge about employees and customers, and 32\% SNSs created team building opportunities. Employees also reported that social networking has become part of the culture of their workplace (AT\&T, 2008).

From the organizational perspective, a social networking site is the quickest way to collect information. "Organizations are actively leverage the power of social networks to find new business opportunities, new groups of like-minded individuals and companies, and new sources of industry specific wisdom, advice and expertise" (Wilson, 2009). SNSs authorize organizations to store and transmit information of different marketing strategies and procedures. Organization presence can be maintained through social networking in the workplace. It also acts as a marketing tool to assist the organization to reach out potential employees. Wilson (2009) noted that "a logical extension of this is to employ people to spend their entire day maintaining the sanctioned organization presence on various social networking sites, acting as an organization's voice".

Some employers at present rely on social networking sites for recruitment process to reduced recruiting costs, and bunch of curriculum vitae generated by job boards can be lessen. Social networking tools can facilitate job applicants to their assessment procedures. A survey conducted for CareerBuilder.com found $45 \%$ of employers were utilizing social networking to screen potential employees, more than double from the year earlier. Eisele (2006) asked 1,000 biggest organizations in Germany about their experiences with Internet and recruitment. He found out that $67 \%$ saw the use of web-based solutions as an improvement of their recruitment processes, $49 \%$ of them practiced it and achieved lower recruitment costs. It also shows that the use of some form of e-recruitment methods reduced the hiring costs about $87 \%$ in comparison to common traditional recruitment tools like newspapers (Lee, 2005); Cober et al., 2001). Thus, it is generally accepted that using Social Networking Sites for recruitment can make an outstanding impact to the reduction of the recruitment costs and employee productivity as well.

\subsection{ISSUES OF SNS TO ORGANIZATIONS}

Despite the significance and contribution of SNS to organizations as mentioned above, the widespread use of SNS in the workplace poses many challenges as it changes the way people interact within the organization. According to Wilson (2009), there are five principal risks that organization has in regard to social networking: perceived loss in staff productivity, data leakage from staff gossiping freely in an open environment, damage to a business's reputation, scam practiced by cyber crooks, and the open access to organization information due to outdated passwords.

Posting on social networking sites is also vulnerable to cyber criminal activities by disseminating wrong information which can cause embarrassment to the organization concerned. For example, five years ago, Krasner (2007) posted an issue on Google's health advertising blog regarding her negative view of Michael 
Moore's healthcare movie "sicko". This issue imputes a lot of criticism and attention from Google users around the world. According to the blog, this issue is just a Google opinion because it was posted on company's blog. In the end, they admitted that the internal review of issue failed to distinguish before it was brought out of the site. This kind of employee's behavior could damage a company's reputation. "Employers have the right to hold employees responsible for such conduct if the postings are used to 'attack the company' or 'harass coworkers"” (Breslin, 2009). In another case, 13 cabin crew of Virgin Atlantic Airplane were fired after they posted disrepute messages about the safety standards of airplane and insulting passengers using social networking (Quinn, 2008).

In a related development, Peacock (2008) noted that "employers worry that staff are wasting time on websites during the work hours, weakening productivity and increasing security risks to the company by sharing data externally". In addition, employees who spend more time on social networking sites such as Facebook has resulted in many employers banning the use of the sites during work hours (Benzie, 2007). Nevertheless, unproductive employees will find ways to be unproductive without using the internet. Proper supervision and performance policies are the real solution to this concern (Cornelius, 2009). A study conducted by Nucleus Research with 237 corporate employees shows that $77 \%$ of employees checking websites during work hours resulted in $1.5 \%$ decrease in employee productivity for those organizations allowing access to social networking sites in the workplace (Gaudin, 2009). It was obvious that productivity of employees was dropped due to addictive and excessive browsing and uploading photos which were not related to the workplace.

With regards to personal privacy, employees who have uploaded their individual profiles cannot stop the distribution of them. According to the statistics of Facebook for 2012, there are 250 million "photos" uploaded daily, 2.7 billion "likes" every day, and 37 million "pages" with 10 plus likes (Fach, 2012). Given this immense number of personal information may eventually lend in the hand of criminals or culprit employers who may cause harm to the employees and family members. Presently, many employers try to hook up in the world of social networking to see the other side of employee's personality before giving the job offer. An example of this, the president of consulting firm in Chicago decided to investigate one of the applicant's social networking pages, and he found of descriptions of marijuana, shooting people, and obsessive sex (Mooney, 2009).

\subsection{SOCIAL NETWORKING AND EMPLOYEE PRODUCTIVITY}

In general, productivity of an employee is measured in terms of labor hours spent by him/her on the given task. Bernolak (1997:204) defined productivity as how much and how well employee produces from the given resources. There are basically two types of employees which are the main taskforce of any organization: the blue-collar employee and the white-collar employee. Blue-collar employees are considered as the backbone of any organization because they are the maker of the finished good; they work in factories and workshop to manufacture the ultimate consumable goods. In December 2010, ISTAT conducted a survey to 19,000 households and individuals and found that $48 \%$ of blue-collar employees were uneasy when exposed to computing sites, unlike $85 \%$ white-collar employees who found the opposite.

Durant (2010) claimed that Takeshi Numoto, Corporate Vice President of Office Product Management Group, submitted a post, "Productivity + social networking = goodness for the workplace". In it, if influenced in a different way, social networking can help organizations be more productive and employees in the workplace form a group that fosters a culture of diversity, respect, and openness. It facilitates organizations with the incredible knowledge and information that need to stay on top of business industry (Breakenridge, 2010).

\section{CONCLUSION}

The three main purposes of this exploratory study were to (i) investigate the relevance of collaborative technology such as social networking to employee productivity in the workplace, (ii) examine positive and negative perceptions of social networking sites, and (iii) provide relationship between social networking and employee productivity. Social networking generally stimulates collaboration and knowledge sharing between individuals, which can lead to increased or decreased productivity. But social networking should be channelled in an effective way to get maximum results from the employees, as there are pitfalls that employees may succumb to it, if left unattended (Ferreira \& du Plessis, 2009). Some of the risks include network security breaches and bandwidth costs, network performance issues, legal liability, business information leaks (Wavecrest, 2009), if all these are kept in mind, then social networking sites may be a boon than a curse. To maximise the potential of social networking within the organization, it is recommended that employers implement policies and strategies to increase the benefits of uses of social networking sites among their employees. 


\section{A Conceptual Analysis of Social Networking and its Impact on Employee Productivity}

To overcome for decreased employee productivity, employers should develop a statistical and measurable way to rate each employee's actual production, and then balance those numbers against the cost of each employee. After that, take a proactive approach to support employees in their tasks. The more information each employee has, the more he will feel empowered to execute his tasks with confidence and direction. If employees are working so hard and delivering results on time, then it should not matter if they are visiting social networking sites while they are at work. It is also important to treat employees with respect and tact, causing them to be even more productive and increase their loyalty to the organizations. Social networking sites are capable of increasing the levels of employee performance and satisfaction when used wisely and efficiently.

\section{References}

[1]. AT\&T (2008): Social Networking in the Workplace Increases Efficiency, http://www.corp.att.com/emea/ insights/pr/eng/ social_111108.html, November 11 .

[2]. Beck, A. (2007), “Web 2.0: Konzepte, Technologie, Anwendungen. HMD," - Praxis der Wirtschaftsinformatik. 44 (255), 5-16.

[3]. Benzie, R. (2007). Facebook banned for Ontario staffers, TheStar.com, http://www.thestar.com/news/article/210014--facebookbanned-for-ontario-staffers, May 3.

[4]. Bernolak, I. (1997). "Effective measurement and successful elements of company productivity: the basis of competitiveness and world prosperity," International Journal of Production Economics 52:203-213.

[5]. $\quad$ Boyd, D.M. \& Ellison, N.B. (2008). "Social Network Sites: Definition, History, and Scholarship," J Compur-Mediat Comm. $2008(13), 210-230$.

[6]. Breslin, T. (2009). 'When social networking enters the workplace' Massachusetts Nurse, 80(8), 14. Retrieved fromhttp://ezproxy.neumann.edu:2048/login?url=http://search.ebscohost.com/login.aspx?direct=true\&db=a9h\&AN=44347496\& site=ehost-live.

[7]. CareerBuilder.com (2009). Career Expert Provides DOs and DON'Ts for Job Seekers on Social Networking, http://www.careerbuilder.com/share/aboutus/pressreleasesdetail.aspx?id=pr519\&sd=8\%2F19\%2F2009\&ed=12\%2F31\%2F2009, August 19.

[8]. Cober, R.T., Brown, D.J., Blumental, A.J., \& Levy, P.E. (2001). "The quest for the qualified job surfer: It`s time the public sector catches the wave," Public Personnel Management, 29, 479-494.

[9]. Cornelius, D. (2009). Online Social Networking: Is It a Productivity Bust or Boon for Law Firms?, Law Practice Magazine, http://www.americanbar.org/publications/law_practice_home/law_practice_archive/lpm_magazine_articles_v35_is2_pg28.html.

[10]. Cruz, F.M. \& Tombado, J.M. (2010). The influence of using Social Networking Sites at work on Filipino employees' productivity and interpersonal relationships, http://iskwiki.upd.edu.ph/index.php/The_influence_of_using_Social_Networking_Sites_ at_work_on_Filipino_employees\%E2\%80\%99_productivity_and_interpersonal_relationships.

[11]. Deloitte, LLP (2009). Social networking and reputational risk in the workplace, Ethics \& Workplace Survey Results, http://www.deloitte.com/assets/Dcom-UnitedStates/Local\%20Assets/Documents/us_2009_ethics_workplace_survey_ 220509 .pdf.

[12]. Durant, John (2010). Social Networking and Workplace Productivity, http://blogs.msdn.com/b/johnrdurant/archive / 2010/03/ 02/social-networking-and-workplace-productivity.aspx, March 2.

[13]. Eisele, S. (2006). Online-Recruiting: Strategien, Instrumente, Perspektiven. Saarbrücken:VDM Verlag Dr. Müller.

[14]. Fach, M. (2012). Statistics on Facebook 2012, http://www.search enginejournal.com/stats-on-facebook-2012-infographic/40301/ February 17.

[15]. Fahmy, Miral (2009). Facebook, YouTube at work make better employees, Reuters, Yahoo Tech, http://tech.yahoo.com/news/nm/20090402/wr_nm /us_work_internet_tech_life, April 2.

[16]. Ferreira, A. \& du Plessis T. (2009). "Effect of online social networking employee productivity". Peer Reviewed Article Vol.11 (1).

[17]. Gaudin, S. (2009). Study: Facebook use cuts productivity at work, http://www.computerworld.com/s/article/9135795/Study_ Facebook_use_cuts_productivity_at_work, July 22

[18]. Goldfield, B. (2011). How Social Networks Can Boost Productivity, http://www.reuters.com/article/2011/02/28/ idUS333008144720110228, February 28.

[19]. Greenwald, J. (2009). Employees' social networking raises employers' liability risk, Business Insurance, Retrieved from http://www.businessinsurance.com/article/20090719/ISSUE01/307199966, July 20.

[20]. ISTAT - Italian National Institute of Statistics (2010). "ICT Usage - Household and Individuals". http://en.istat.it/salastampa/comunicati/in_calendario/nuovetec/20101223_00/ICT_households_2010.pdf.

[21]. Krasner, M. (2007). Google and Health Care". Google blogspot, http://googleblog.blogspot.com/2007/07/google-and-healthcare.html, July 2.

[22]. Lee, I. (2005). "The evolution of e-recruiting: a content analysis of Fortune career web sites" Journal of Electronic Commerce in Organizations, 3, 57-68.

[23]. Martensen, M., Borgmann, L. \& Bick, M. (2011). The Impact of Social Networking Sites on the Employer-Employee Relationship, In: proceedings of $24^{\text {th }}$ Bled eConference eFuture: Creating Solutions for the Individual, Organizations and Society, Bled, Slovenia, June 12-15.

[24]. Mitrano, T. (2006). Thoughts on Facebook. Cornell Information Technologies, Retrieved March 2, 2010 from http://www.Cit.cornell.edu/policies/socialnetworking/ facebook.cfm

[25]. Mooney, C. (2009). "Online Social Networking”. Gale Cengage Learning.

[26]. Nicholson, S. (2011). Infographics: The history of online social networking, http://socialmediatoday.com/ socmedsean/286629/infographic-history-online-social-networking, April 17.

[27]. Peacock, L. (2008). Employers watch Facebook usage, Employers' Law, Retrieved from: http://www.lexisnexis.com/us/lnacademic/results/docview/docview.do?docLinkInd=true\&risb=21_T7917082304\&format=GNB FI\&sort=RELEVANCE\&startDocNo=1\&resultsUrlKey=29_T7917082307\&cisb=22_T7917082306\&treeMax=true\&tree Width $=0 \&$ csi $=274986 \&$ docNo=1, April 11.

[28]. Picot, A. \& Neuburger, R. (2000). Internet-Ökonomie. Wirtschaftsdienst - Zeitschrift für Wirtschaftspolitik. Sonderdruck 10 (80), 591-606. 
A Conceptual Analysis of Social Networking and its Impact on Employee Productivity

[29]. Quinn, B. (2008). Virgin sacks 13 over Facebook 'chav' remarks, http://www.guardian.co.uk/business/2008/nov/01/virginatlantic-facebook, November 1 .

[30]. Snopes.com, (2005). Internet of Lies, http://www.snopes.com/ quotes/ internet.asp, May 5.

[31]. Wavecrest Computing, (2009). Social Networking or Social Not-working, http://www.wavecrest.net/editorial/include/ SocialNetworking_SocialNotworking.pdf

[32]. Wilson, J. (2009). "Social networking: the business case," [Electronic Version] Engineering \& Technology (4)10 54-56, June 6. 